\title{
Amethocaine gel reduced pain during venipuncture in newborn infants
}

\section{Jain A, Rutter N. Does topical amethocaine gel reduce the pain of venepuncture in newborn infants? A randomised double blind controlled trial. Arch Dis Child Fetal Neonatal Ed 2000 Nov;83:F207-10.}

\section{QUESTION: Does topical amethocaine gel reduce pain during venipuncture in newborn infants?}

\section{Design}

Randomised (allocation concealed), blinded (patients, clinicians, outcome assessors), placebo controlled trial with follow up immediately after the procedure.

\section{Setting}

Postnatal wards and the neonatal intensive care unit at the Nottingham City Hospital, Nottingham, UK.

\section{Patients}

40 newborn infants (median age $7 \mathrm{~d}$, median gestational age 33 wks) who required venipuncture as part of their routine care. Infants who were unwell, ventilated, or sedated were excluded. Follow up was $98 \%$.

\section{Intervention}

20 infants were allocated to $1.5 \mathrm{~g}$ of $4 \%$ amethocaine gel and 20 were allocated to $1.5 \mathrm{~g}$ of placebo gel. The gel was applied to the dorsum of the hand or foot and covered with an occlusive dressing. After 1 hour, the dressing was removed, the gel was wiped away, and the infant was left to settle for 5 minutes. A neonatal senior house officer or an advanced neonatal nurse practitioner did the venipuncture using a 21-ST needle.

\section{Main outcome measures}

2 authors independently assessed pain reaction at 1 second intervals, beginning 5 seconds before needle insertion and ending 5 seconds after insertion using the neonatal facial coding system (NFCS) (maximum cumulative score of 25 over a 5 second period). Main outcomes were proportion of infants who showed no or minimal pain reaction to venipuncture (NFCS score $\leqslant 10$ in the 5 seconds after needle insertion) and proportion who did not cry in the 5 seconds after needle insertion. Other outcomes included number of attempts to obtain the blood sample and number of local skin reactions.

\section{Main results}

More infants who received amethocaine gel had minimal or no pain compared with infants who received placebo gel, and more did not cry at all (table). The groups did not differ for proportion of blood samples collected on the first attempt $(79 \% v 65 \%, \mathrm{p}=0.3)$, and no local skin reactions were observed.

\section{Conclusion}

Topical amethocaine gel reduced pain during routine venipuncture in newborn infants.

\author{
Source of funding: \\ Higher Education \\ Funding Council. \\ For correspondence: \\ Dr A Jain, Department of \\ Neonatal Medicine \\ Nottingham City \\ Hospital, Hucknall \\ Road, Nottingham \\ NG5 $1 P B$, UK. Fax +44 \\ (0)1159627926
}

Topical amethocaine gel v placebo during venipuncture in newborn infants*

\begin{tabular}{lllll} 
Outcomes & Amethocaine & Placebo & RBI (95\% Cl) & NNT (Cl) \\
$\begin{array}{l}\text { Proportion who had little or no } \\
\text { pain with needle insertion }\end{array}$ & $84 \%$ & $30 \%$ & $181 \%(52$ to 490$)$ & 2 (2 to 5$)$ \\
\hline $\begin{array}{l}\text { Proportion who did not cry at } \\
\text { all in the } 5 \text { seconds after } \\
\text { needle insertion }\end{array}$ & $79 \%$ & $25 \%$ & $216 \%(56$ to 624$)$ & 2 (2 to 5$)$ \\
\hline
\end{tabular}

*Abbreviations defined in glossary; RBI, NNT, and $\mathrm{Cl}$ calculated from data in article.

\section{COMMENTARY}

Venipuncture is a painful, invasive procedure commonly performed on newborn infants in hospital. Few options have been available to clinicians for reducing the pain associated with such procedures. Until recently, studies evaluating the use of amethocaine gel were done solely in adult and paediatric populations. The study by Jain and Rutter is the first to assess the effectiveness of this new topical anaesthetic in newborn infants.

Amethocaine gel is a potential therapeutic breakthrough for procedural pain management in infants. When compared with EMLA (eutectic mixture of local anaesthetics), amethocaine gel has the added benefits of a shorter application time, longer duration of effect, and lower cost; however, it is only licensed for use in full term infants $>1$ month old.

This study is important and well designed. Strengths include the use of an identical placebo control and good inter-rater reliability among the researchers who assessed pain. More research is needed, however, before we can safely use amethocaine gel in newborn and preterm infants. The ideal dose and application times for infants need to be safely established; doses used in published studies range from $0.5-1.5 \mathrm{~g}$ with application times of 30-60 minutes. ${ }^{1-3}$ Many infants, especially those in neonatal intensive care, require multiple venipunctures and intravenous insertions during their hospital stay, and the effect of repeated dosing in a short period is not known. Additional research addressing these outstanding issues would be required before using amethocaine gel in clinical practice with newborn and preterm infants.

Marilyn Ballantyne, RN, MHSc Clinical Nurse Specialist/Neonatal Nurse Practitioner The Hospital for Sick Children Program Director, Post Masters NP Diploma Faculty of Nursing, University of Toronto Toronto, Ontario, Canada

1 Woolfson AD, McCafferty DF, Boston V. Clinical experiences with a novel percutaneous amethocaine preparation: prevention of pain due to venepuncture in children. Br J Clin Pharmacol 1990;30:273-9.

2 Lawson RA, Smart NG, Gudgeon AC, et al. Evaluation of an amethocaine gel preparation for percutaneous analgesia before venous cannulation in children. Br J Anaesth 1995;75:282-5.

3 Bishai R, Taddio A, Bar-Oz B, et al. Relative efficacy of amethocaine gel and lidocaine-prilocaine cream for port-a-cath puncture in children. Pediatrics 1999;104:e31. 